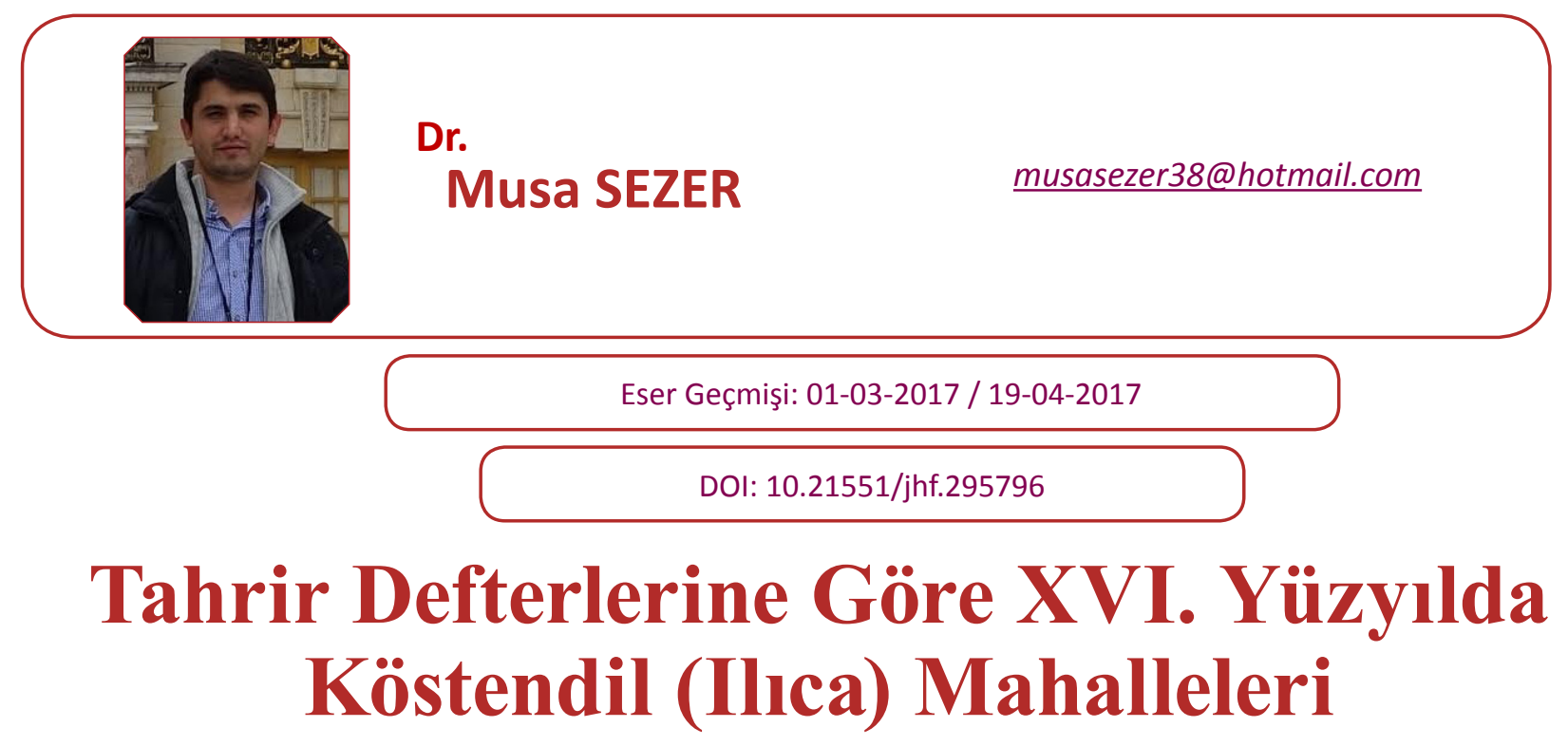

\title{
According to Tahrir Registers, Neighbourhoods of Kyustendil in XVIth Century
}

\section{ÖZET}

Tarihte Ilıca ismiyle de anılan Köstendil șehri günümüzde, Bulgaristan'ın batısında Sırp, Makedon ve Bulgar sınırlarının kesiştiği bölgede yer almaktadır. 1372'de Sultan I. Murad tarafından fethedilen Köstendil, 1395 yılından sonra Osmanlı sancağı haline getirilmiștir. Rumeli Beylerbeyliği'ne bağlı bir sancak olan Köstendil, XV. yüzyılın başlangıcından itibaren yürütülen iskân ve imar faaliyetleri ile bir dönüm noktasına girmiş ve Osmanlı şehri hüviyetine kavuşmuştur. XVI. yüzyılda ilk tahrir ve son tahrir arasında geçen 53 yılda nüfusu iki katına ulaşan şehirde önemli oranda Müslüman nüfus bulunuyordu. Bu çalışmada XVI. yüzyıl tahrir defterlerine göre Köstendil'de yaşayan Müslüman ve gayrimüslim nüfusun ortaya konulması amaçlanmıştır. Nüfusun artmasıyla kurulan Müslüman mahalleleri üzerinde durularak, bu mahallelerin tahrirlere göre nüfus durumları karşılaştırılmıştır. Ayrıca Müslüman nüfus artışındaki sürekliliğin nedenleri ortaya konulmuştur.

Anahtar Kelimeler: Osmanlı İmparatorluğu, Köstendil, Ilıca, Mahalle, Nüfus, Tahrir Defterleri

\section{ABSTRACT}

Kyustendil city, which is also known as "Ilıca" name in history, is located nowadays in the West of Bulgaria where the Serb, Macedonian and Bulgarian boundaries intersect. Kyustendil was conquered by the Sultan Murad the First in 1372 and after 1395 it was became an Ottoman Sanjak. Kyustendil, which is a part of Rumelia Province, has entered to the turning point starting from the beginning of the 15th century with the execution of development and housing activities and reached the identity of being an Ottoman city. At the 16th century in 53 years between the first census and last census, the population of Kyustendil has doubled and there were Muslim residents in significant ratio. In this study, 
it has been aimed to put forward the Muslim and non-Muslim population living in Kyustendil according to the 16th century census books. By dwelling on the Muslim neighbourhood establishments with the increase in population, the population status of these neighbourhoods are being compared according to the censuses. In addition, the reasons behind the continuity of increase in Muslim population have been revealed.

Keywords: Ottoman Empire, Kyustendil, Ilica, Neighbourhood, Population, Tahrir Registers

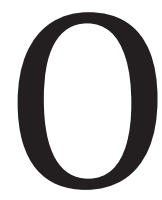

smanlı Devleti zamanında Rumeli Beylerbeyliği'ne tabi olan Köstendil, günümüzde Bulgaristan sınırları içinde, Bulgaristan'ın batısında ${ }^{1}$ ve Sofya'nın 86 km güneyinde bulunmaktadır. Şehir, antikçağda Pautalia, Ortaçağda Velbujd $^{2}$ ve Osmanlılar zamanında Köstendil şeklinde anılmıștır. Köstendil isminin arşiv belgelerinde değişik formlarda kaydedildiği görülmektedir. XV. yüzylla ait belgelerde Kostadin ili, ${ }^{3}$ Kostadin, Ilıca, ${ }^{4}$ Kostadin Ilıcası $^{5}$ olarak, XVI. yüzyllda ise Köstendil, Ilıca, Köstendil Ilıcası ${ }^{6}$ ve Banya-i Köstendil ${ }^{7}$ şekillerinde kaydedilmiştir. Burada geçen banya, ılıca ve kaplıca anlamına gelmekte olup çok sayıda sıcak su hamamından dolayı şehir "Ilıca" ismiyle de anılmıştır.

Köstendil ismi ise şehrin son yöneticisi Sırp Konstantin Dejanoviç'e ${ }^{8}$ ithafen Konstantin'in şehri anlamında Kostadin-ili'nden gelmektedir.

Sultan Murad beş yıl Rumeli'de kaldıktan sonra 1370'de Bursa'ya dönmüș, ${ }^{9}$ 1372'de Lala Şahin'in fetihlerini tamamlamak üzere tekrar Rumeli'ye geçmiş ve Velbujd tekfuru Konstantin'in üzerine yürümüştür. ${ }^{10}$ Konstantin, topraklarının genişliği ve askerlerinin çokluğu ile tanınan bir kişiydi. Ancak sultanın geldiği haberini alınca karşılık gösterdiği takdirde yenileceğini anladığı için Osmanlı padișahını hediyelerle karşılamış ve ona bağlılığını bildirmiştir. Onun bu bağlılığı şehrin yöneticisi olarak kalmasını sağlamıştır. ${ }^{11}$ Konstantin'in

1 Machiel Kiel, “Köstendil”, Türkiye Diyanet Vakfı Íslam Ansiklopedisi (DİA), C.26, Diyanet Vakfi Yay., Ankara 2002, s.277.

2 Stamen Mikhailov, Maria Sestrimska, The Old School in Kyustendil (Materials from Archaeological Excavations), Bulgarski Houdozhnik Publishing House, Sofia 1981, s.5-6.

3 NBKM. D. 707, vr. 5b.

4 BOA. MAD.d. 149, vr.1b, $2 \mathrm{a}$.

5 NBKM. OAK. 214/5, vr. 16a-17a.

6 BOA. MAD.d. 170, vr.490a, 491a.

7 BOA. KK.d. 67, s.32. "Banya-i Köstendil Kadısı Mevlana Muhyiddin'e hüküm yazıla ki; Kaza-i Banya'dan ...”

8 Kiel, a.g.m., s.277; Machiel Kiel, "Küstendil”, The Encyclopaedia of Islam, V, Leiden 1979, s.534.

9 Mehmed Neşri, Kitâb-ı Cihan-nümâ Neşrî Tarihi, C.I, Yay. Faik Reşit Unat, Mehmed A. Köymen, TTK., Ankara 1995, s.197.

10 Halil İnalcık, "Murad I", Türkiye Diyanet Vakfi Íslam Ansiklopedisi (DİA), C.31, Türkiye Diyanet Vakfı Yay., İstanbul 2006, s.159.

11 Mehmed Hemdemi Solakzâde, Solakzâde Tarihi, C.I, Haz. Vahid Çabuk, Kültür Bakanlığı Yay., Ankara 1989, s.47-48; Müneccimbaş1 Ahmed b. Lütfullah, Camiü'd-Düvel Osmanlı Tarihi (1299-1481), Haz. Ahmet Ağırakça, İnsan Yay., İstanbul 1995, s.111; İsmail Hami Danişmend, İzahlı Osmanlı Tarihi Kronolojisi, C.I (1258-1512), 
I. Murad'a itaat etmesi anonim bir tarihte "773 târîhinde ümerâ-yı Rûm-ili istir'âsıyla pâdşâh-ı cihân, Rûm-ili cânibine mürûr buyurup diyâr-ı Bulgar hâkimi Köstendil tekfuri Kostantin üzerine asker çekildikde ita'at idüp mahallinde takrîr olundı"12 şeklinde anlatılmıştır.

Köstendil'in Osmanlı sancağı haline getiriliş tarihi tam olarak bilinmemekle birlikte Niğbolu ve Ohri'nin sancak olmasıyla aynı döneme denk geldiği düşünülmektedir. Osmanlılar, Yıldırım Bayezid döneminde 17 Mayıs 1395'de Argeş Nehri civarında Rovine'de Eflaklarla karşılaşmıştı. Bu savaşa Osmanlılar safında Makedonya Sırp vasallarından Stephan Lazareviç, Kral Marko ve Köstendil yöneticisi Konstantin de katılmış, bu mücadele sırasında Marko ile Konstantin hayatını kaybetmiştir. ${ }^{13}$ Konstantin'in Rovine Savaşı'nda hayatını kaybetmesi üzerine prensliği Osmanlı hâkimiyeti altına girmiș ve kısa bir süre belirsiz bir statüde kaldıktan sonra Köstendil Sancağı hâline getirilmiştir. ${ }^{14}$

Köstendil'in alınmasıyla ileride yapılan seferlerde şehrin, bir harekât üssü olarak kullanıldığı anlaşılmaktadır. Nitekim Osmanlı'nın batıya yaptığı seferlerde kullandığı Orta Kol sefer güzergâhında, Filibe'den ikiye ayrılıp Üsküp'e giden ikinci yolda bulunan Köstendil, ${ }^{15}$ Sultan I. Murad'ın 1389'da Kosova Savaşı'na giderken konakladığı ve ordusunun birçok ihtiyacını karşıladığı yer olmuştur. ${ }^{16}$ Ayrıca 1463'te Fâtih Sultan Mehmed Bosna seferine giderken Köstendil yolunu takip etmiștir. ${ }^{17}$

Sancak haline getirilişinden sonraki yıllar Köstendil için bir dönüm noktası olarak görülmektedir. Nitekim bundan sonra şehre ilk olarak Konya'dan 60 Türk ailesi getirilip yerleştirilmiştir. ${ }^{18}$ Bunun haricinde Osmanlı Devleti'nin ele geçirdiği yerlerde sistemli bir şekilde iskân politikası uyguladığı bilinmektedir. Fetihlerle birlikte yerleşik Hristiyan halk daha iç ve dağlık bölgelere göç etmiş ve onlardan boşalan yerlere ise Anadolu'dan getirilen Türkmenler yerleștirilmiștir. Bu yerleștirmeler daha ziyade Bulgaristan'a yapılmıștır. ${ }^{19}$ Illk fetihlerin ardından Orhan Gazi döneminden itibaren Rumeli'ye yapılan yerleştirmeler ${ }^{20}$ ve fetihlerin artmasıyla Batı Anadolu Yörüklerinin Rumeli'de Bulgaristan'ın hemen tamamından Makedonya'ya kadar olan bölgelerde iskân edilmesi, buraların Türkleşmesine etki etmiștir. ${ }^{21}$ Öyle ki, Anadolu'dan Rumeli'ye nakledilen Yörükler yerleștikleri bölgelerde

Türkiye Yay., İstanbul 1971, s.52-53.

12 Anonim Tevârîh-i Âl-i Osman (Kuruluştan 892/1487'ye kadar), Haz. Cihan Çimen, Marmara Üniversitesi Türkiyat Araştırmaları Enstitüsü, Yayınlanmamış Yüksek Lisans Tezi, İstanbul 2006, s.27.

13 Hatice Oruç, Makedonya'da Osmanlı Egemenliğinin Kurulması, Ankara Üniversitesi Sosyal Bilimler Enstitüsü, Yayınlanmamış Yüksek Lisans Tezi, Ankara 1997, s.99.

14 Rossitsa Gradeva, “Orta Balkanlar’da Osmanlı İdari Sistemi ve Taşra İdaresi (XV. Yüzyıl)”, Türkler, C.9, Yeni Türkiye Yay., Ankara 2002, s.919.

15 Halime Doğru, “Osmanlı Devleti’nin Rumeli’de Fetih ve İskân Siyaseti”, Türkler, C.9, Yeni Türkiye Yay., Ankara 2002, s.165-166.

16 Mehmed Neşri, a.g.e., s.263, 265, 267.

17 Machiel Kiel, "Köstendil”, Türkiye Diyanet Vakfi İslam Ansiklopedisi (DIA), C.26, Diyanet Vakfi Yay., Ankara 2002, s.278.

18 Dimana Trankova, Anthony Georgieff, Hristo Matanov, A Guide to Ottoman Bulgaria, Sofia 2011, s.155.

19 Mehmet İnbaşı, “Balkanlar'da Osmanlı Hâkimiyeti ve İskân Siyaseti”, Türkler, C.9, Yeni Türkiye Yay., Ankara 2002, s. 158 .

20 Hava Selçuk, Rumeli'de Osmanlı İskan Siyaseti (1299-1481), Erciyes Üniversitesi Sosyal Bilimler Enstitüsü, Yayınlanmamış Doktora Tezi, Kayseri 2002, s.66.

21 Mehmet İnbaşı, “XVI-XVII. Yüzyıllarda Bulgaristan’daki Yörük Yerleşmeleri”, Uluslararası Osmanlı ve 
kendi dil ve kültürlerini buralara taşımışlardır. Bunların birçoğu adı Türkçe olan yeni köy ve yerleşim birimleri kurmuşlardır. Bu açıdan bakıldığında Osmanlı fetih ve iskânlarının geçici, maceracı ve çapulcu hareketi olmadığı, kesin bir yerleştirme ve yurt edinme gayesi güttüğü anlaşılmaktadır. ${ }^{22}$ Bu şehirlerden biri olan Köstendil şehrinde de yapılan iskânlarla nüfus artmış ve imar faaliyetleri hız kazanmıștır. İnşa faaliyetleriyle șehir halkı daha önce sahip olmadığı ve sosyal hayatta ihtiyaç duyduğu yapılara kavuşmuştur. Nüfus artışı ve imar faaliyetleriyle Osmanlılar tarafından yurt olarak kabul edildiği anlaşılan Köstendil, artan Müslüman nüfusu sonucu birçok mahalleye ayrılmıştı.

\section{Müslüman Mahalleleri}

XVI. yüzyll tahrir defterlerinden anlaşıldığına göre cami, mescit, medrese, zaviye, ılıca, han ve hamam gibi yapılarıyla Türk-İslam şehri görünümünde olan Köstendil, artan nüfusu dolayısıyla birçok mahalleye ayrılmıștı. Şehirde Müslüman ve gayrimüslim nüfus ayrı mahallelerde ikamet etmekteydi. 1572 tarihli defterde kaydedilen küçük bir Yahudi azınlık, Müslüman mahallelerinde ikamet ediyordu. 1550 tarihli tahrir kaydında rastlanmayan bu azınlığın bu iki zaman dilimi arasında gelip yerleştikleri anlaşılmaktadır. ${ }^{23}$ Köstendil'de, dolayısıyla șehrin merkezi olan Ilıca'da Müslüman mahalleleri șu şekildeydi.

Tablo 1: XVI. Yüzyılda Ilıca'da Müslüman Mahalleleri

\begin{tabular}{|l|l|l|l|}
\hline \multicolumn{1}{|c|}{$\mathbf{1 5 1 9}^{1}$} & \multicolumn{1}{c|}{$\mathbf{1 5 3 0}^{\mathbf{2}}$} & \multicolumn{1}{c|}{$\mathbf{1 5 5 0}^{3}$} & \multicolumn{1}{c|}{$\mathbf{1 5 7 2}^{4}$} \\
\hline Cami & Cami-i Kebir & Cami-i Kebir/Cami-i Şerif & Cami-i Kebir/Cami-i Şerif \\
\hline Hacı İbrahim & Hacı İbrahim & Hacı İbrahim Mescidi & Hacı İbrahim Mescidi \\
\hline Ahmed Fakih & Ahmed Fakih & Ahmed Fakih & Ahmed Fakih \\
\hline Hacı Dündar & Hacı Dündar & Hacı Dündar & Hacı Dündar \\
\hline Kara Mehmed & Kara Mehmed & Kara Mehmed Mescidi & Kara Mehmed Mescidi \\
\hline- & - & Murad Çelebi Mescidi & Murad Çelebi Mescidi \\
\hline- & - & Hacı Alagöz Mescidi & Hacı Alagöz Mescidi \\
\hline- & - & Kara Hasan Mescidi & Kara Hasan Mescidi \\
\hline- & - & Hacı Ömer Mescidi & Hacı Ömer Mescidi \\
\hline- & - & Bayezid Ağa Mescidi & Bayezid Ağa Mescidi \\
\hline- & - & Muslihiddin Hoca Mescidi & Muslihiddin Hoca Mescidi \\
\hline- & - & Muslihiddin Mescidi & Muslihiddin Mescidi \\
\hline- & - & Halil Paşa İmareti Mescidi & Halil Paşa İmareti Mescidi \\
\hline- & - & Hacı Ömer & Hacı Ömer \\
\hline- & - & Hacı Ali Mescidi & Hacı Ali Mescidi \\
\hline- & - & Alaybeyi Mescidi & Alaybeyi Mescidi \\
\hline
\end{tabular}

Cumhuriyet Dönemi Türk-Bulgar Illişkileri Sempozyumu (11-13 Mayls 2005) Bildiriler, Eskişehir 2005, s.171172.

22 Mehmet İnbaşı, "Balkanlar'da Osmanlı Hâkimiyeti ...”, s.159.

23 Musa Sezer, XVI. Yüzyılda Köstendil Ilıcası, Erciyes Üniversitesi Sosyal Bilimler Enstitüsü, Yayınlanmamış Doktora Tezi, Kayseri 2017, s.95. 


\begin{tabular}{|c|c|c|c|}
\hline- & - & Süleyman Bey Vakfı Mescidi & Süleyman Bey Vakfi Mescidi \\
\hline- & - & Kaya Bey Mescidi & Kaya Bey Mescidi \\
\hline- & - & - & Abdurrahim Efendi Mescidi \\
\hline- & - & - & Osman Çelebi \\
\hline- & - & - & Hacı İvaz Mescidi \\
\hline- & - & - & Kurd Çelebi ${ }^{5}$ \\
\hline 5 & 5 & 18 & 22 \\
\hline
\end{tabular}

Tabloda da görüldüğü üzere 1519 ve 1530 tarihlerinde beş olan mahalle sayısı büyük bir artışla 1550'de 18 ve 1572'de 22'ye yükselmiști. 1550 ve 1572 'de mahalle sayılarında görülen büyük artış Müslüman nüfus artışıyla alakalıdır. ${ }^{24}$ Yukarıdaki tarihlere ait tahrir defterlerinde kaydı bulunmayan bir mahalle, 1581 tarihli celepkeşan defterinde geçmektedir. Mahmud Çelebi Mahallesi ${ }^{25}$ olan bu mahalle ile XVI. yüzyılın sonlarına doğru Ilıca'da mahalle sayısının 23'e yükseldiği görülmektedir. Şehrin kurucuları ve önemli kişilerinden olan Ahmed Fakih, Hacı Dündar, Kara Mehmed, Kaya Bey ve Süleyman Bey'in isimlerinin mahallelere verildiği anlaşılmaktadır. Mahalle isimleri arasında hacı, hoca, fakih, çelebi, ağa, efendi ve bey gibi unvanlar bulunmaktaydı.

1519 ve 1550 tarihli mufassal tahrir defterlerinde Müslüman mahallelerinde isim altlarına o kişinin hangi vergi mükellefi olduğuna dair işaretlerin düzenli olarak eklenmediği ve eklenenlerin ise toplandığında yekun ile çeliştiği anlaşılmaktadır. Bu sebeple 1519 ve 1550 'de mahallelerin nüfus durumları tek tek tespit edilememekte, ancak toplam olarak bir değer çıkarılabilmektedir. Dolayısıyla belirtilen tarihlere ait nüfus verileri bu çalışmada toplam olarak mahalleler sonunda verilecektir. 1572'de ise vergi mükelleflerinin düzenli olarak kaydedilmesi sayesinde tek tek mahallelerin nüfusları tespit edilebilmektedir.

\section{Cami Mahallesi ${ }^{26}$}

Tahrir kayıtlarında 1519'da Cami, 1530'da Cami'-i Kebir, 1550 ve 1572'de Cami'-i Kebir ve Cami'-i Șerif, 1576 ve 1581 tarihli celepkeșan defterlerinde ise Cami'-i Atik olarak kaydedilmiştir. 1550'de yine ilk sırada olup ismi verilmeyen mahallenin, Cami Kebir Mahallesi olduğu sonrasında kaydedilen Murad Mescidi Mahallesi'nden ${ }^{27}$ anlaşılmaktadır. Buna benzer kaydın 1572 tarihli defterde de olduğu görülmektedir. ${ }^{28}$

Mahallede bulunan cami, XVI. yüzyıl tahrir defterlerinden anlaşıldığına göre Haraççı Kara Mehmed tarafından yaptırılıp, Fatih Sultan Mehmed'e ithaf edilmiştir. Günümüzde harap bir halde bulunan cami o zamandan beri Fatih Cami adıyla anılmıștır. ${ }^{29}$

24 Musa Sezer, a.g.t., s.96.

25 BOA. MAD.d. 4075, s.11; Dragan Amedoski, Tatyana Katiç, "Köstendil Kazasının 1581 Tarihli Celepkeşân Defteri (5 belge ile birlikte)", Belgeler, C. XXXIII, S. 37, Ankara 2012, s.5.

26 BOA. MAD.d. 170, vr.71a; 167 Numaralı ... I, s.217; BOA. TT.d. 267, s.21; TKG. KK. TT.d. 88, vr.10a-10b;

NBKM. $\Phi 95 / 23$, s.4; BOA. MAD.d. 4075, s.10; Amedoski, Katiç, a.g.m., s.4.

27 BOA. TT.d. 267, s.21. "Mahalle-i Mescid-i Murad Çelebi tabi Cami-i Kebir"

28 TKG. KK. TT.d. 88, vr.10a.

29 Musa Sezer, a.g.t., s.156. 
1519'da cami imamı Muhiddin bin Muslihiddin ve müezzin Hıdır bin Ali idi. Mahallede 1530'da 73 hane, 12 mücerred, altı akıncı ve bir hatip yaşıyordu. 1550'de imam Ahmed Fakih ve imam Kasım bin Abdullah, müezzin İbrahim bin Hasan ve hatip Hüsam Halife bin Eymir idi. 1572 'de ise imam olarak Hacı Ömer bin Hasan ve hatip olarak Hüsam Halife bin Eymir görev yapıyordu. 1572'de birer imam, hatip, müezzin ve madenci bulunurken, ikișer akıncı ve celep, 52 hane ve 13 mücerred kaydedilmişti.

\section{Hacı İbrahim Mahallesi ${ }^{30}$}

Bu mahalle 1519 ve 1530'da Hacı Íbrahim, 1550 ve 1572'de ise Hacı İbrahim Mescidi ismiyle yazılmıştır. Mahallede 1519'da bir imam bulunurken, 1530'da üç imam vardı. Ayrıca 1530 'da 44 hane, 18 mücerred ve üç akıncı yaşıyordu. 1550'de imam olarak Şemseddin ve Receb bin Şemseddin, müezzin olarak ise Mustafa bin Yahya ve Hasan bin Mürvet görev yapıyordu. 1572'de ise imam Şemseddin bin Yusuf ve müezzin Nasuh bin Yahya idi. 1572'de birer imam, müezzin ve muhassıl bulunan mahallede, üçer akıncı ve celep, 32 hane ve sekiz mücerred ikamet ediyordu.

\section{Ahmed Fakih Mahallesi ${ }^{31}$}

Ahmed Fakih Mahallesi'nin 1519'da imamı Muhiddin bin Yusuf olup, 1530'da iki imamı vardı. 1550'de imam Receb bin Bali Hoca ve müezzin Hacı Bali bin Abdullah'ın görev yaptığı mahallede, 1572 yılında imam Hüsam Halife ve müezzin Eymir Halife idi. 1572'de birer imam, müezzin, akıncı ve celebin olduğu mahallede 36 hane ve beş mücerred yaşıyordu.

\section{Hacı Dündar Mahallesi}

Hacı Dündar ismine, ilk defa 3 Mayıs 1478'de Ilıca'da kethüda olduğuna dair kayıtta rastlanmaktadır. Hacı Dündar, daha sonraki kayıtlarda köy olduğu görülen Gırlani mezrasında timar sahibi idi. ${ }^{32} 1478$ 'de yaşadığı görülen Ilıca kethüdası Hacı Dündar'ın ismi mahalleye verilmiş olmalıdır.

$\mathrm{Bu}$ mahalle, XVI. yüzyıl tahrir defterlerinde Hacı Dündar, $1576^{33}$ ve 1581 tarihli celepkeşan defterinde ise Hacı Dindar ${ }^{34}$ olarak kaydedilmiști. 1519'da mahalle imamı ve hatibi Şaban bin Mahmud, müezzini ise Mehmed bin Bedreddin idi. ${ }^{35} 1530$ 'da mahallede din görevlisi olarak bir imam, 34 hane, yedi mücerred ve dört akıncl ${ }^{36}$ yaşıyordu. 1550'de imam Ahmed Halife, müezzin Piri bin Mustafa ve hatip Ahmed Hoca idi. ${ }^{37} 1572$ 'de ise imam olarak

30 BOA. MAD.d. 170, vr.71b-72a; 167 Numaralı ... I, s.217; BOA. TT.d. 267, s.24-25; TKG. KK. TT.d. 88, vr.13a; NBKM. Ф95/23, s.4.

31 BOA. MAD.d. 170, vr.72a; 167 Numaralı ... I, s.217; BOA. TT.d. 267, s.23; TKG. KK. TT.d. 88, vr.12b; NBKM. Ф95/23, s.4.

32 BOA. MAD.d. 7219, s.52.

33 NBKM. $\Phi 95 / 23$, s.2.

34 BOA. MAD.d. 4075, s.10; Amedoski, Katiç, a.g.m., s.4.

35 BOA. MAD.d. 170, vr.72b.

36167 Numaralı ... I, s.217.

37 BOA. TT.d. 267, s.22-23. 
Süleyman Halife ve müezzin olarak Ahmed bin Karamani bulunuyordu. Bu tarihte mahallede birer imam ve müezzin, iki muhassıl, üçer akıncı ve celep, 61 hane ve yedi mücerred yaşıyordu. ${ }^{38}$

\section{Kara Mehmed Mahallesi ${ }^{39}$}

Tahrirlerde 1519 ve 1530'da Kara Mehmed șeklinde geçen mahalle, 1550 ve 1572'de Mescid-i Kara Mehmed olarak kaydedilmiştir. 1519'da imam olarak Hacı Muslihiddin görevli idi. 1530'da din görevlisinin kaydedilmediği mahallede 28 hane, üç mücerred, dört akıncı ve bir sipahizâde yaşıyordu. 1550'de imam İbrahim bin Davud ve müezzin Mustafa bin Mehmed iken, 1572'de imam Sinan Halife ve müezzin Pir Mehmed idi. Mahallede görevli imam ve müezzin haricinde 1572 'de 26 hane vardı.

\section{Halil Paşa İmareti Mescidi Mahallesi ${ }^{40}$}

1519 ve 1530 yıllarında mahalle olarak geçmemekle birlikte, "Cemaat-i hüddâm imâret-i merhum Halil Paşa" şeklinde Hacı Dündar Mahallesi'ne tabi idi. 1550 ve 1572'de ise mahalle olarak kaydedilmişti. Mahallede 1519'da imam Muhiddin ve müezzin Mustafa haricinde üç kiși daha bulunuyordu. 1530'da ise bir imam ve 10 hane vardı. 1550'de mahalle mescidi imamı Seydi ve müezzini Ali idi. Bu tarihte "Cemaât-i Hüddâm İmaret-i merhum Halil Paşa ...” başlığı altında Şeyh İskender bin Abdullah, nâib Merdan Hoca, Şeyh Muhiddin bin Hıdır, nekkâri İskender bin Abdullah, vekilharç Mehmed bin Aydın, kâtib Mahmud bin Çekik Nasuh ve debbağ Şaban bin Abdullah gibi yedi görevli ismi kaydedilmişti. Bunlar Halil Paşa İmareti Mescidi'nde hizmetli kimselerdi. 1572'de mahallede imam olan Alaaddin Halife ve ayrıca 36 hane yaşıyordu.

\section{Murad Çelebi Mescidi Mahallesi ${ }^{41}$}

1550 ve 1572 tarihlerinde Cami Kebir Mahallesi'ne tabi olan bu mahalle, her iki tarihte de aynı isimle kaydedilmiştir. 1550'de mahallede müderrisler Şemseddin ve Cafer bin Yusuf yaşıyordu. Mahallede 1572'de dokuz hane, yedi mücerred, iki madenci ile birer akıncı ve celep bulunuyordu.

\section{Hacı Alagöz Mescidi Mahallesi ${ }^{42}$}

1550 ve 1572 'de aynı isimle kaydedilen mahalle, Cami Kebir Mahallesi'ne tabi idi. Mahallede 1550'de imam Yusuf bin Süleyman ile müezzin Ataullah bin Kurd haricinde birer mütevelli ve faraş vardı. Toplam 22 ismin kaydedildiği mahallede yedi kişi Koşeva madeni çalışanlarından oluşuyordu. Aynı tarihte dört de akıncı bulunuyordu. 1572'de bu mescidin imamı Sinan Halife idi ve 15 hane ile iki mücerred yaşıyordu. Mahallede Müslümanlardan başka iki hane Yahudi ailesi vardı.

38 TKG. KK. TT.d. 88, vr.11b-12a.

39 BOA. MAD.d. 170, vr.72b-73a; 167 Numaralı ... I, s.217; BOA. TT.d. 267, s.22; TKG. KK. TT.d. 88, vr.11a; NBKM. $\Phi 95 / 23$, s.5.

40 BOA. MAD.d. 170, vr.72b; 167 Numarall ... I, s.217; BOA. TT.d. 267, s.23; TKG. KK. TT.d. 88, vr.12a.

41 BOA. TT.d. 267, s.21; TKG. KK. TT.d. 88, vr.10b.

42 BOA. TT.d. 267, s.21; TKG. KK. TT.d. 88, vr.10b. 


\section{Kara Hasan Mescidi Mahallesi ${ }^{43}$}

1550 ve 1572'de Cami Şerif Mahallesi'ne tabi olan bu mahallenin 1550'de imamı Şeyh Salih ve müezzini Receb idi. 1572'de imam ve müezzin kaydedilmeyen mahallede 42 hane, beș mücerred ile ikişer akıncı ve celep yaşıyordu.

\section{Hacı Ömer Mescidi Mahallesi ${ }^{44}$}

1550 tarihli kayıttan bu mahallenin bir önceki mahalle olan Kara Mehmed Mescidi Mahallesi'ne tabi olduğu anlaşılmaktadır. Bu tarihte mescidin imamı Eşrefzâde ve müezzini Mehmed, 1572'de ise imamı Hacı Rıdvan ve müezzini Ahmed bin Mahmud idi. Ayrıca 1572'de mahallede yedi hane ile birer tane muhassıl ve celep vardı.

\section{Bayezid Ağa Mescidi Mahallesi ${ }^{45}$}

Mahalle mescidinin 1550'deki imamı İbrahim Hoca ve müezzini Salih Hoca, 1572'de ise imamı Muslihiddin ve müezzini Süleyman idi. Bu mahallede 1572'de din adamlarından başka 20 hane ve bir muhassıl yaşıyordu.

\section{Muslihiddin Hoca Mescidi Mahallesi ${ }^{46}$}

Mahalle'de 1550'de müezzin olarak Hasan bin Hüseyin görev yapıyordu. 1572'de ise imam Mehmed bin Yusuf ve müezzin Mahmud bin Ahmed idi. Ayrıca 1572'de 14 hane ve altı mücerred bulunuyordu.

\section{Muslihiddin Mescidi Mahallesi ${ }^{47}$}

1550 ve 1572 tarihlerinde Hacı Dündar Mahallesi'ne tabi olan mahallede bir mescit bulunmaktaydı ve bu mescitte 1550'de imam İbrahim ile müezzin Mahmud, 1572'de ise imam Hüsam Halife görevliydi. Mahallede 1572'de dört akıncı, birer celep ve haraççı, 16 hane ve beş mücerred kayıtlıydı.

\section{Hacı Ömer Mahallesi ${ }^{48}$}

Mahalle 1550 ve 1572'de Ahmed Fakih Mahallesi'ne tabi olup, 1550'de imam Cafer bin Yusuf ve müezzin Mehmed bin Hamza idi. 1572'de ise imam Muhyiddin Halife ve müezzin Mehmed Halife görev yapıyordu. Mahallede 1572'de birer imam, müezzin ve akıncı ile 24 hane ve dört mücerred yaşıyordu.

\footnotetext{
43 BOA. TT.d. 267, s.21-22; TKG. KK. TT.d. 88, vr.10b-11a.

44 BOA. TT.d. 267, s.22; TKG. KK. TT.d. 88, vr.11a.

45 BOA. TT.d. 267, s.22; TKG. KK. TT.d. 88, vr.11a.

46 BOA. TT.d. 267, s.22; TKG. KK. TT.d. 88, vr.11b.

47 BOA. TT.d. 267, s.23; TKG. KK. TT.d. 88, vr.12a.

48 BOA. TT.d. 267, s.23-24; TKG. KK. TT.d. 88, vr.13a.
} 


\section{Hacı Ali Mescidi Mahallesi ${ }^{49}$}

Ahmed Fakih Mahallesi'ne bağlı olan mahallede, 1550'de mescit müezzini Bekir bin Karagöz idi. 1572 tarihli tahrir kaydında birer müezzin, akıncı ve celep ile dokuz hane ve üç mücerred vardl.

\section{Alaybeyi Mescidi Mahallesi ${ }^{50}$}

Yine bu mahalle de 1550 ve 1572'de Ahmed Fakih Mahallesi'ne tabi idi. Mahalle mescidinin müezzini 1550'de Hasan Şeyh ve imamı Talib idi. 1572'de ise imam olarak Musa Halife ve müezzin olarak Mehmed bin Hasan görevliydi. Ayrıca 1572'de birer akıncl, celep ve muhassıl ile 31 hane ve yedi mücerred yaşıyordu.

\section{Süleyman Bey Vakfı Mescidi Mahallesi ${ }^{51}$}

1550 ve 1572 tarihli kayıtlarda Hacı İbrahim Mahallesi'ne tabi olan mahallede bir vakıf mescidi bulunuyordu. Bu mescidin imamı 1550'de Hamza ve müezzini Abdullah bin Mustafa, 1572 'de ise imamı Muhyiddin bin Hıdır ve müezzini Hacı bin Alişan idi. 1572'de birer imam, müezzin, muhassıl ve sipahinin bulunduğu mahallede, 11 hane ve iki mücerred kaydı vardı.

\section{Kaya Bey Mescidi Mahallesi}

Kaya Bey, Ilıca'nın önemli şahsiyetlerinden olan Mamak Bey'in, oğullarından Hızır Bey'in oğlu idi. Kaya Bey'in dedesi Mamak Bey'e Fatih Sultan Mehmed tarafindan mülk olarak verilen Ilıca'ya bağlı Jabokut (Jabokırd) köyü, Mamak Bey'in ölümünden sonra oğullarına ve sonra da torunlarına intikal etmiști. Kaya Bey, buranın gelirlerinin kendi hissesine düşen kısmı ile Ilıca'da bir mescit yaptırmış ve masraflarını da yine kendi hissesinden karşılıyordu. ${ }^{52}$

1550 ve 1572'de Hacı İbrahim Mahallesi'ne bağlı olan mahallede bulunan mescidin imamı 1550'de Alaaddin Hoca ve müezzin Hacı Hamza bin Hüseyin idi. 1572'de ise imam Şemseddin Halife bin Hacı Kasım ve müezzin Receb bin Şemseddin görev yapıyordu. 1572'de toplam olarak birer imam, müezzin, akıncı ve diğer görevlinin bulunduğu mahallede ayrıca üç madenci, beş mücerred ve sekiz hane yaşıyordu. ${ }^{53}$

\section{Abdurrahim Efendi Mescidi Mahallesi ${ }^{54}$}

Kaydına sadece 1572 tarihli defterde rastlanan bu mahalle Kara Mehmed Mahallesi'ne tabi idi. Mahalle imamı Seydi Ali ve müezzini Hasan bin Hacı Mahmud idi. Ayrıca birer muallim, muhassıl ve sipahizâde bulunan mahallede dokuz hane ve üç mücerred kaydedilmişti.

\footnotetext{
49 BOA. TT.d. 267, s.24; TKG. KK. TT.d. 88, vr.13a. 50 BOA. TT.d. 267, s.24; TKG. KK. TT.d. 88, vr.12b. 51 BOA. TT.d. 267, s.25; TKG. KK. TT.d. 88, vr.13b. 52 Musa Sezer, a.g.t., s.163-165.

53 BOA. TT.d. 267, s.25; TKG. KK. TT.d. 88, vr.13b. 54 TKG. KK. TT.d. 88, vr.11a-11b.
} 


\section{Osman Çelebi Mescidi Mahallesi ${ }^{55}$}

1572'de kaydedilen mahalle, Ahmed Fakih Mahallesi'ne tabi idi. Mahallede imam olarak İbrahim bin Musa ve müezzin olarak Mehmed bin Yusuf görevliydi. Bunlardan başka bir akıncı, iki celep, altı mücerred ve 25 hane bulunuyordu.

\section{Hacı İvaz Mescidi Mahallesi ${ }^{56}$}

Bu mahallede 1572'de görevli imam İbrahim bin Mehmed ve müezzin Musa bin Nasuh idi. Mahallede ayrıca birer akıncı ve celep ile 38 hane ve üç mücerred yaşıyordu. Mahalle sonuna kaydedilen iki Yahudi hanesinin Müslümanlarla birlikte aynı mahallede yaşadığı anlaşılmaktadır.

\section{Kurd Çelebi Mahallesi ${ }^{57}$}

1572 tarihli tahrir defterlerinin vakıf kayıtları cildinde kaydedilen mahalle ismine, burada tesis edilmiş olan Mehmed Han Vakfı'na ait iki çeşmeden bahsedilmesi vesilesiyle rastlanmaktadır. Bu çeşmeler mahallenin suyunun yeterli olmaması üzerine yaptırılmıştı. Mahallenin nüfusu ile ilgili ise bir bilgi bulunmamaktadır.

\section{Mahmud Çelebi Mahallesi}

Tahrir defterlerinde kaydı bulunmayan bu mahalle, 1581 tarihli celepkeşan defterinde geçmektedir. ${ }^{58}$ Burada geçen kayıttan mahalle isminin tespiti haricinde nüfus verisi elde edilememiştir.

Buraya kadar haklarında bazı bilgiler verilen Ilıca mahallelerinin elde edilen nüfus verileri, nüfus işlemlerinde uygulanan yaygın formül ( $\mathrm{h} \times 5+\mathrm{m}=$ tahmini nüfus) ${ }^{59}$ ile işleme tabi tutulursa mahallelerin XVI. yüzyıldaki nüfusuyla ilgili aşağıdaki tahmini veriler elde edilebilir.

Tablo 2: XVI. Yüzyılda Ilıca Şehir Merkezinde Müslüman Nüfusu

\begin{tabular}{|l|l|l|l|l|l|l|l|l|}
\hline & \multicolumn{2}{|c|}{$\mathbf{1 5 1 9}^{6}$} & \multicolumn{2}{c|}{$\mathbf{1 5 3 0}^{7}$} & \multicolumn{2}{c|}{ 1550 $^{8}$} & \multicolumn{2}{c|}{ 1572 $^{9}$} \\
\hline \multirow{2}{*}{ Nüfus Durumu } & h. & m. & h. & m. & h. & m. & h. & m. \\
\cline { 2 - 8 } & 293 & 60 & 317 & 58 & 385 & 64 & 628 & 91 \\
\hline Tahmini Nüfus & \multicolumn{2}{|c|}{1.525} & \multicolumn{2}{|c|}{1.643} & \multicolumn{2}{c|}{1.989} & 3.231 \\
\hline
\end{tabular}

h.: hane, m.: mücerred

55 TKG. KK. TT.d. 88, vr.12a-12b.

56 TKG. KK. TT.d. 88, vr.13b.

57 TKG. KK. TT.d. 89, vr.402a.

58 BOA. MAD.d. 4075, s.11; Amedoski, Katiç, a.g.m., s.5.

59 Hanenin genellikle beş kişiden oluştuğu kabul edilmektedir. Her hanenin 5 ile çarpılıp üzerine mücerredlerin eklenmesiyle elde edilen sayı, şehrin tahmini nüfusunu göstermektedir. Ömer Lütfi Barkan, "Tarihî Demografi Araştırmaları ve Osmanlı Tarihi”, Türkiyat Mecmuası, C.X, İstanbul 1953, s.11-12. 
Görüldüğü üzere Ilıca'da Müslüman nüfusunda her tahrirde artış yașanmıștı. Bu artış $1519-1530$ arası $\%$ 7,74; $1530-1550$ arası \% 21,05 ve $1550-1572$ arası $\% 62,44$ oranında gerçekleşmişti. 1519 ile 1572 arasında geçen 53 yıllık zaman zarfında Ilıca nüfusu ikiye katlanmıștı.

Şehir merkezinde bir hayli yüksek olan Müslüman nüfus artışı, Ilıca'da XVI. yüzyıl boyunca süren refaha bağlıdır. XVI yüzyılda üretim düzeyi göstergelerindeki sürekli artış, ekonomik refahın Ilıca'da var olduğunu göstermektedir. Dolayısıyla üretimin artmasıyla refah düzeyi yükselmiş ve bu durum XVI. yüzyılda Ilıca'nın nüfusunda yükselişlere neden olmuştur. ${ }^{60}$ Gayrimüslimlerden İslamiyet'i seçenlerin de Müslüman nüfus artışında etkili olduğunu söylemek yerinde olsa gerektir. Nitekim bilindiği üzere sonradan Müslüman olanların baba adı "Abdullah" olarak değiştirilmekteydi. ${ }^{61}$ Ancak Abdullah isminin Müslümanlar arasında sevilen bir isim olmasıyla yeni doğan Müslüman çocuklara verilebileceği de düşünülmelidir. Sonuçta Ilıca'da 1519'da 44, 1550'de 94 ve 1572'de ise 188 kişinin baba adı Abdullah idi. Verilen bu sayısal ifadelerle Ilıca'da Müslüman nüfus artışında, diğer bir ifadeyle de aşağıda görüleceği üzere gayrimüslim nüfus artışının fazla olmamasında ihtida hareketlerinin de etkisi olmuş olmalıdır.

\section{Gayrimüslim Mahalleleri}

XVI. yüzyılda Ilıca'da gayrimüslimler "Cemaat-i Gebran" ya da "Mahalle-i Gebran"62 şeklinde kaydedilmişlerdi ve dolayısıyla özel bir isimle anılan mahalleye sahip değillerdi.

Gayrimüslim olarak nitelendirilen Hristiyan reaya haricinde, şehirde 1572'de Hacı Alagöz Mescidi Mahallesi'nde iki hane ${ }^{63}$ ve Hacı İvaz Mescidi Mahallesi'nde iki hane ${ }^{64}$ olmak üzere toplam dört Yahudi hane yaşıyordu. Yahudiler kendilerine ait bir mahallede değil, belirtilen Müslüman mahallelerinde sakindiler.

Nüfusun sürekli artış gösterdiği Ilıca'da Müslümanlar haricindeki halkın nüfus durumu şu şekildeydi.

Tablo 3: XVI. Yüzyılda Ilıca Şehir Merkezinde Gayrimüslim Nüfusu

\begin{tabular}{|l|l|l|l|l|l|l|l|l|l|l|l|l|l|}
\hline & \multicolumn{3}{|c|}{1519} & \multicolumn{3}{c|}{1530} & \multicolumn{3}{c|}{1550} & \multicolumn{3}{c|}{1572} \\
\hline \multirow{2}{*}{ Nüfus Durumu } & h. & m. & b. & h. & m. & b. & h. & m. & b. & h. & m. & b. & Yh. \\
\cline { 2 - 13 } & 47 & 6 & 8 & 47 & 4 & 1 & 64 & 9 & 10 & 82 & 28 & 14 & 4 \\
\hline Tahmini Nüfus & \multicolumn{3}{|c|}{249} & \multicolumn{3}{c|}{240} & \multicolumn{3}{c|}{339} & \multicolumn{2}{c|}{452} & 20 \\
\hline
\end{tabular}

h.: hane, m.: mücerred, b.: bive, Yh.: Yahudi hane

60 Ayrıntılı bilgi için bkz. Musa Sezer, a.g.t., s.104.

61 Ahmet Yiğit, "İzmir Şer’iyye Sicillerine Yansıyan İhtida Vakaları”, Uluslararası Sosyal Araştırmalar Dergisi The Journal of International Social Research, Volume 3/11 Spring 2010, s.639.

62 BOA. MAD.d. 170, vr.73a; 167 Numaralı ... I, s.217; BOA. TT.d. 267, s.25-26; TKG. KK. TT.d. 88, vr.14a-14b.

63 TKG. KK. TT.d. 88, vr.10b.

64 TKG. KK. TT.d. 88, vr.13b. 
Yaygın formülün uygulanmasıyla gayrimüslim nüfusu için tabloda görülen tahmini değerler elde edilmiştir. Buna göre gayrimüslim nüfusunda 1530'da yaşanan küçük bir düşüş haricinde genelde bir artış yaşanmıştı. Bu verilerden yola çıkarak gayrimüslim reaya nüfusunda 1519-1530 arası \% 3,6’lık bir düşüşün yaşandığı, 1530-1550 arası yaklaşık \% 41'lik ve 1550-1572 arası \% 33'lük bir artışın yaşandığı tespit edilmektedir. 1572'de dört hane olan Yahudi nüfus ise 20 olarak ortaya çıkmaktadır. Müslüman ve gayrimüslim nüfus artışı arasında bir karşılaştırma yapılacak olursa özellikle 1519-1550 ve 1550-1572 arası dönemlerde gayrimüslim nüfus artış hızının Müslüman nüfusa oranla oldukça düşük seviyelerde kaldı̆̆ı gözlenmektedir.

\section{SONUÇ}

1372'de I. Murad tarafından fethedilen Köstendil, yöneticisi Konstantin'in 1395 Rovine Savaşı'nda Osmanlı saflarında savaşırken hayatını kaybetmesinden kısa bir süre sonra Osmanlı Devleti'nin bir sancağı haline getirilmiștir. Orta Kol sefer güzergâhında, Filibe'den ikiye ayrılıp Üsküp'e giden ikinci yolda bulunan Köstendil'in alınmasıyla ilerde yapılacak seferlerde üs olarak kullanıldığı anlașılmaktadır. Köstendil, bünyesinde bulunan çok sayıda kaplıca ve hamam nedeniyle Ilıca olarak da anılmıștır. Şehre yapılan iskânlar ve bundan sonra hız kazanan mimari gelişmeler şehri Türk-İslam şehri haline getirmiştir.

XVI. yüzyllda artan nüfusun etkisiyle şehirde birçok yeni mahalle kurulmuştur. 1519 ve 1530 'da beş olan mahalle sayısı 1550'de 18 ve 1572 'de 22'ye yükselmiştir. Köstendil'deki Müslüman mahallelerinin genelde Türk-İslâm mahalle özelliklerinde olduğu gibi bir mescit ya da caminin etrafında geliştiği anlaşılmaktadır. Mutlaka bir cami ya da mescidin bulunduğu Köstendil Müslüman mahalleleri, bulunduğu mescit ya da caminin adıyla anılmıştır. $\mathrm{Bu}$ isimlerin Köstendil'in imarında emeği geçen önemli şahsiyetler olduğu görülmektedir. Hacı Dündar, Kara Mehmed ve Halil Paşa bunlardan bazılarıdır. XVI. yüzyıla ait tahrirler üzerinde yapılan incelemede Müslüman nüfusun gayrimüslimlere oranla çoğunlukta olduğu tespit edilmiștir. Müslüman nüfusun, Ilıca'da toplam nüfusun 1519'da \% 86'sını, 1530'da \% 87'sini, 1550 'de \% 85'ini ve 1572'de \% 87'sini teșkil ettiği ortaya konulmuștur. Bu artıșta XVI. yüzyll boyunca şehirde süren refahın etkili olduğu gözlenmiştir. Ayrıca ihtida hareketlerinin bu artışa etki ettiği baba adı "Abdullah" olanların sayısındaki artışlardan anlaşılmıştır. Baba adı Abdullah olanlarda 1519'dan 1572'ye kadar dört kattan fazla bir artış yaşanmıştır.

Ilıca'da yaşayan gayrimüslimlerin tek bir isim adı altında "Mahalle-i Gebran” şeklinde kaydedildikleri ve müstakil mahalleler kuramadıkları görülmüştür. Bu durum da nüfus yoğunluklarının fazla olmamasıyla alakalı olmalıdır. Gayrimüslim nüfusunda Müslümanlara oranla önemli bir artış olmamakla birlikte yine de bir yükseliş söz konusu olmuştur. Artan Müslüman nüfusu ile birçok Müslüman mahallesine ayrılan Ilıca'nın, Türk-İslam şehri özelliklerine sahip olduğu anlaşılmıştır. 


\section{KAYNAKÇA}

\section{A. Arşiv Kaynakları}

\section{Başbakanlık Osmanlı Arşivi (İstanbul):}

MAD.d. 170, MAD.d. 149, MAD.d. 4075, MAD.d. 7219, TT.d. 267, KK.d. 67.

\section{Tapu ve Kadastro Genel Müdürlüğü, Kuyûd-ı Kadîme Arşivi (Ankara):}

TT.d. 88, TT.d. 89.

\section{St. Kiril ve Metodiy Milli Kütüphanesi (Sofya) (NBKM): \\ D. 707 , OAK. $214 / 5, \Phi 95 / 23$}

\section{B. Araştırma ve İnceleme Eserleri}

167 Numaralı Muhâsebe-i Vilâyet-i Rûm-ili Defteri (937/1530) I <Dizin ve Tıpkıbasım>, Başbakanlık Osmanlı Arşivi Yay., Ankara 2003.

AMEDOSKİ, Dragan; KATİÇ Tatyana, “Köstendil Kazasının 1581 Tarihli CelepkeşânDefteri (5 belge ile birlikte)”, Belgeler, C. XXXIII, S. 37, Ankara 2012, ss.1-20.

Anonim Tevârîh-i Âl-i Osman (Kuruluştan 892/1487'ye kadar), Haz. Cihan Çimen, Marmara Üniversitesi Türkiyat Araștırmaları Enstitüsü, Yayınlanmamış $\quad$ Yüksek Lisans Tezi, İstanbul 2006.

BARKAN, Ömer Lütfi, “Tarihî Demografi Araştırmaları ve Osmanlı Tarihi”, Türkiyat Mecmuasl, C.X, İstanbul 1953, ss.1-26.

DANİ̧MEND, İsmail Hami, İzahlı Osmanlı Tarihi Kronolojisi, C.I (1258-1512), Türkiye Yay., İstanbul 1971.

DOĞRU, Halime, “Osmanlı Devleti'nin Rumeli'de Fetih ve İskân Siyaseti”, Türkler, C.9, Yeni Türkiye Yay., Ankara 2002, ss.165-176.

GRADEVA, Rossitsa, “Orta Balkanlar'da Osmanlı İdari Sistemi ve Taşra İdaresi (XV. Yüzyıl)”, Türkler, C.9, Yeni Türkiye Yay., Ankara 2002, ss.916-925.

İNALCIK, Halil, "Murad I", Türkiye Diyanet Vakfı İslam Ansiklopedisi (DİA), C.31, Diyanet Vakfi Yay., İstanbul 2006, ss.156-164.

İNBAŞI, Mehmet, “Balkanlar'da Osmanlı Hâkimiyeti ve İskân Siyaseti”, Türkler, C.9, Yeni Türkiye Yay., Ankara 2002, ss.154-164.

---------, “XVI-XVII. Yüzyıllarda Bulgaristan'daki Yörük Yerleşmeleri”, Uluslararası 
Osmanlı ve Cumhuriyet Dönemi Türk-Bulgar İlişkileri Sempozyumu (11-13 Mayıs 2005) Bildiriler, Eskişehir 2005, ss.171-187.

KİEL, Machiel, "Köstendil”, Türkiye Diyanet Vakfı İslam Ansiklopedisi (DİA), C.26, Diyanet Vakfı Yay., Ankara 2002, ss.277-279.

---------, “Küstendil”, The Encyclopaedia of Islam, V, Leiden 1979, ss.534-535.

---------, “Ottoman Kyustendil in the 15th and 16th Centuries”, Turco-Bulgarica Studies On The History Settlement And Historical Demography Of Ottoman Bulgaria, The Isis Press, İstanbul 2013, ss.193-234.

Mehmed Hemdemi Solakzâde, Solakzâde Tarihi, C.I, Haz. Vahid Çabuk, Kültür Bakanlı̆̆ı Yay., Ankara 1989.

Mehmed Neşri, Kitâb-ı Cihan-nümâ Neşrî Tarihi, C.I, Yay. Faik Reşit Unat, Mehmed A. Köymen, TTK., Ankara 1995.

Müneccimbaşı Ahmed b. Lütfullah, Camiü'd-Düvel Osmanlı Tarihi (1299-1481), Haz. Ahmet Ağırakça, İnsan Yay., İstanbul 1995.

MİKHAİLOV, Stamen; SESTRİMSKA, Maria, The Old School in Kyustendil (Materials from Archaeological Excavations), Bulgarski Houdozhnik Publishing House, Sofia 1981.

ORUÇ, Hatice, Makedonya'da Osmanlı Egemenliğinin Kurulması, Ankara Üniversitesi Sosyal Bilimler Enstitüsü, Yayınlanmamış Yüksek Lisans Tezi, Ankara 1997.

SELÇUK, Hava, Rumeli'de Osmanlı İskan Siyaseti (1299-1481), Erciyes Üniversitesi Sosyal Bilimler Enstitüsü, Yayınlanmamış Doktora Tezi, Kayseri 2002.

SEZER, Musa, XVI. Yüzyılda Köstendil Ilıcası, Erciyes Üniversitesi Sosyal Bilimler Enstitüsü, Yayınlanmamış Doktora Tezi, Kayseri 2017.

TRANKOVA, Dimana; GEORGIEFF, Anthony; MATANOV, Hristo, A Guide to Ottoman Bulgaria, Sofia 2011.

YİĞİT, Ahmet, "İzmir Şer'iyye Sicillerine Yansıyan İhtida Vakaları", Uluslararası Sosyal Araștırmalar Dergisi-The Journal of International Social Research, Volume 3/11 Spring 2010, ss.633-648.

\section{Tablo içi dipnot kaynakçası}

1 BOA. MAD.d. 170, vr.71a-73a.

2167 Numaralı Muhâsebe-i Vilâyet-i Rûm-ili Defteri (937/1530) I <Dizin ve Tıpkıbasım>, Başbakanlık Osmanlı Arşivi Yay., Ankara 2003, s.217. 
3 BOA. TT.d. 267, s.21-25.

4 TKG. KK. TT.d. 88, vr.10a-13b.

5 TKG. KK. TT.d. 89, vr.402a. Bu mahalle ismine 1572 tarihli defterlerin vakıf kayıtları cildinde, Köstendil sancakbeylerinden Mehmed Han Vakfi'na ait iki çeşmeden bahsedilmesi vesilesiyle rastlanmıştır. Mahalle nüfusu ile ilgili bilgi yoktur. Aynı tarihe ait Ilıca mahallelerinden olduğu için tabloya eklenmiştir.

6 BOA. MAD.d. 170, vr.73a.

7167 Numaralı ... I, s.217; Machiel Kiel, “Ottoman Kyustendil in the 15th and 16th Centuries", Turco-Bulgarica Studies On The History Settlement And Historical Demography Of Ottoman Bulgaria, The Isis Press, İstanbul 2013, s.208.

8 BOA. TT.d. 267, s.21-26.

9 TKG. KK. TT.d. 88, vr.10a-14b. 